\title{
Self-directed Learning in Preparatory-year University Students: Comparing Successful and Less-successful English Language Learners
}

\author{
Fatimah M. A. Alghamdi ${ }^{1}$ \\ ${ }^{1}$ English language Institute, King Abdulaziz University (KAU), Jeddah, Saudi Arabia \\ Correspondence: Fatimah Alghamdi, English language Institute, King Abdulaziz University (KAU), Jeddah, \\ Saudi Arabia. E-mail: fmalghamdi@kau.edu.sa
}

Received: January 15, 2016 Accepted: April 29, $2016 \quad$ Online Published: May 13, 2016

doi: $10.5539 /$ elt.v9n7p59

URL: http://dx.doi.org/10.5539/elt.v9n7p59

\begin{abstract}
There is consensus among those involved in teaching English as a foreign language (EFL) in the Saudi educational context that students' achievement in language learning is below expectations. Much research has been directed towards finding the reasons for low achievement amongst learners. However, very few studies have looked at parameters of learners' agency and learners' responsibility in the learning process. This study examines learners' efforts at self-directed learning, measured with reference to a set of behavioral and metacognitive constructs. The primary objective is to diagnose efficiency problems in EFL learning and compare successful learners to those who fail to progress from one academic language level to the next. A secondary objective in this study is to find out if the General Aptitude Test (GAT) score is a predictor of success in language learning.

The findings reveal significant differences between successful learners and less-successful learners in aggregate self-directedness scores. However, while the analysis of the component constructs shows statistically significant differences between successful and less-successful learners in the self-management and study time measures, differences in the self-monitoring and motivation measures were non-significant. The lack of significant differences between some of the measures is attributed to the relative baseline similarity of the two groups. Moreover, the GAT measure yielded a counter-intuitive result; namely that less-successful learners had higher GAT scores than the successful ones, though the difference wasn't statistically significant. The study concludes with implications for further research; for example, calling for a larger scale investigation of self-directedness, as well as other meta-cognitive strategies, and the possible relationship of these to GAT scores. Academic coaching of self-directedness and self-regulation strategies for college students is recommended.
\end{abstract}

Keywords: EFL, Saudi higher education, self-directed learning, self-regulated learning, learner autonomy, metacognitive strategies

\section{Introduction}

Lack of achievement in language learning may be attributed to many factors: cognitive, meta-cognitive, affective, socio-cultural, socioeconomic, and contextual, among others. One of the directions in language learning strategy research is the study of effective strategies. This has often been guided by the theme of 'What good language learners do' when learning a second or foreign language (Rubin, 1975; Stern, 1975; Clément, Dörnyei, \& Noels, 1994; Zimmerman, 1989; Zimmerman \& Bandura, 1994). Stern (1975), for example, listed factors such as defining personal learning plan and self-evaluation as determinants of learning success.

In a study that compared successful and "unsuccessful EFL students", Gan, Humphreys and Hamp - Lyons (2004) collected qualitative data from 18 Chinese university students. They found that successful language learners are influenced by internal and external motivations, with internal ones, "such as interest, learning progress, enhanced self-confidence, and self efficiency" (p. 240), having more influence on students' self-directed learning than external ones. The successful students tend to be optimistic and make use of resources, including teachers. Unsuccessful learners, according to Gan, et al., are aware of their lack of persistence and strong will but seem to attribute their learning problems to factors outside themselves. 


\subsection{The Saudi context}

A number of studies have specifically looked at the Saudi context in terms of problems in learning English as a second or foreign language. See Al-Hazmi (2003), Khan (2011), Al-Nasser (2015), Elyas (2008, 2011, 2014), Elyas and Picard (2010, 2012), and Elyas and Al-Grigeri (2014) for reviews of this issue. One of the concerns prompting many of the investigations of Saudi learners is their generally low achievement in learning English as a foreign language, despite many years of studying English in school and prior to beginning college (Al-Nasser, 2015; Al Shumaimeri, 2003, Elyas, 2008, Elyas \& Picard, 2010). Khan (2011), Elyas (2008), Elyas and Picard (2010), and Fareh (2010), as well as others, provide extended lists of reasons why Saudi learners achieve less in language learning. These include lack of input outside classroom, deficiency (ineffectiveness) of high-school English programs, lack of sufficient training for teachers, and motivation and attitude problems. Similarly, in Elyas's (2014) qualitative investigation of Saudi English learners, students reported on their views of the difficulty of the task of learning English. They included lack of a social context for practicing English and ineffectiveness of high school English curriculum as main sources of difficulty in learning English.

Perhaps, the most striking feature of the Saudi EFL context is the absence of rich L2 linguistic environments. This leads to a lack of opportunities for purposeful communication. One would say, in particular, that the lack of situational urge to perform a task in English often leaves English language users without much socio-cognitive drive. However, regardless of the poor input and lack of communicative opportunities, language learners in Saudi schools and colleges do need to progress in their EFL learning. This is particularly true when they have to learn academic English to pass language courses required for academic advancement in schools and colleges. In such a language learning situation, with poor L2 input and interaction opportunities, a greater responsibility resides with learners. They need to exert effort towards attaining and practicing English language skills.

A number of models have attempted to account for language learning success or failure with reference to the learner's responsibility towards and control over the learning process. Such models have been offered as accounts within a variety of educational contexts for the past forty years or so. Frameworks that offer accounts for learners' autonomy (Holec, 1981; Benson, 2013; Benson \& Lor, 1999; Cotterall, 1995, 1999), self-regulated learning (Zimmerman, 1989; Zimmerman \& Dinsmore, Alexander \& Loughlin, 2008) and self-directed learning (Garrison, 1997; Cotterall \& Murray, 2009) have been very influential in many scholars' attempts to investigate the learner's role in learning a second or foreign language.

This study attempts to investigate language learning difficulties from an individual differences perspective. By doing so, the study assumes that factors that influence language learning could be those that are responsible for problems in learning, in general. Accordingly, a national aptitude test measure was considered as another variable that might predict success in language learning. The General Aptitude Test (GAT), known nationally as 'Qudraat' (the Arabic word for abilities), was introduced into the educational system within the last decade. It assesses higher cognitive functioning as well as linguistic (Arabic) and mathematical competence. GAT is one of the placement measures in Saudi universities and it accounts for $40 \%$ of the weighted grades. The aptitude test and the achievement test are conducted under supervision by the Ministry of Higher Education.

There is a need to investigate factors affecting the achievement of L2 learners, including the control learners have over their behavior, as well as cognitive and meta-cognitive processes. Also, students' readiness to define goals, set agendas for learning, select content and monitor and evaluate their progress must be accounted for. In other words, we need to investigate aspects of the language learning process where the learners have the greatest agency. Learner's agency in and control over the learning process are manifested in a set of metacognitive strategies. The need to quantify these strategies and strategy use has been addressed by introducing models that specifically address the learner's role in the learning process. The most prominent models in this area of research pertain to the notions of 'learner autonomy', 'learner self-regulation' and 'learner self-directedness.'

\subsection{Metacognitive Strategies and Strategy Training in Language Learning}

Prior to the mushrooming of research into self-directed learning and learner autonomy, language learning strategy research often included reference to personal traits of learners that are important for learners' control and task management. For instance, Oxford's (1990) taxonomy of learning strategies divided these traits into cognitive, metacognitive, and affective, among others, and included behavioral and control strategies that can be seen from a perspective of self-directedness.

In a similar vein, Oxford and Nyikos (1989) utilized the Strategy Inventory for Language Learning survey (SILL), Oxford (1990), to detect factors affecting the choice of foreign language learning strategies. Although the particular constructs of autonomy and self-directedness were not identified in their study, Oxford and Nyikos concluded that knowledge of metacognitive strategies, including self-management and self-monitoring, needs to 
be evoked in language learners. Self-management and self-monitoring are in fact two dimensions of learner self-directedness in most frameworks.

Metacognitive strategies are the product of learners' metacognition, i.e., thinking about learning. Wenden (1998) defined metacognitive strategies as "general skills through which learners manage, direct, regulate, and guide their learning" (p. 250). Wenden provided an overview of research on metacognitive strategies and offered a theoretical framework for the role of metacognitive knowledge in language learning, in particular. The model emphasizes the role of metacognitive knowledge in planning, evaluating and monitoring processes within self-regulated learning. It also includes the influence of metacognitive knowledge on other processes, such as task analysis and learning transfer. Relevant also to the present study is Wenden's (1998) view of learners' knowledge about self-efficacy, namely that, "they hold beliefs about their ability to control their learning, i.e. that success is the result of their efforts and not of uncontrollable factors" (p. 226). Language learning strategy research has resulted in the development of scales for measuring strategy use and orientation, and offered models for strategy training. O'Malley and Chamot (1990), in their seminal work on strategy training, developed the Cognitive Academic Language Learning Approach (CALLA), designed to foster learning strategies in high-school second language speakers, both in their language and their subject courses. Relevant to this discussion is the third component of the model that informs CALLA: learning strategies instruction. This provides methods that teachers can use to promote students' autonomy. Similar to this is Oxford's (1990) contribution to the detection and training of learning strategies, mentioned above: SILL. Aiming to help ESL teachers to understand and foster language learning strategies in their students, Oxford provided instructions for administering the SILL survey and outlined implications for strategy training.

\subsection{Learner Autonomy}

One of the earliest definitions of learner autonomy is Holec's (1981), who defined it as, "the ability to take charge of one's learning" (p. 3). Learner autonomy implies learners' readiness to define goals, select content, reflect, plan and evaluate learning. It is "the capacity to make use of strategies that are clearly associated with idea of control of learning" (Benson 2013, p. 62). In general terms, learner autonomy is characterized by an exchange of teachers' and learners' roles and power relationship. It is also a departure from the traditional, socially mediated, learning to more personal control. However, it is not merely more power on the learner's side but also a set of skills and attributes that autonomous learners usually have, such as insight into their learning, a proactive approach, and a critical voice (Thanasoulas, 2000).

Cotterall (1995) investigated learner autonomy in language learning and concluded that autonomous learners are often successful language learners, since "[they] are likely to be individuals who have overcome the obstacles which educational background, cultural norms and prior experience may have put in their way" (p. 200). Moreover, Cotterall (2009) claimed that learner responsibility, managing learning, and reflection are key factors in language learning, together with the more socially constructed factor: affordance. Implications for how to promote learners' autonomy flow from this research. Thanasoulas (2000), for example, suggested self-reports (learners are assigned a task and must report what they are thinking while they are performing it), persuasive communication (modifying learners' beliefs and attitudes), and diaries and evaluation sheets as approaches that show promise for fostering learner autonomy. Benson (2013) identified three categories of autonomy: technical, psychological, and political.

In this study, we are concerned with "learning management," which falls within the technical category. However, the construct of learner autonomy has not been considered in the present study. An inquiry into learner autonomy would be more feasible in contexts where learners can take control and have choice in the process and content of their learning. This condition is not met at the English Language Institute (ELI) of the Saudi university where the present study was carried out. At the ELI, course content, curriculum pacing and student assessment are all predetermined, and neither teachers nor students have any control over them. Yet, some personal attributes within the construct of learner autonomy remain useful in measuring learner role and agency. These include learners' management of the learning context and resources.

\subsection{Self-regulated Learning}

Self-regulation is a concept rooted in psychology. It was initially put forward in connection with explorations of the interactions among a persons' cognition, behavior, and the environment in different contexts, such as health, coping with stress, addiction, etc. ( e.g., Dörnyei \& Ushioda, 2013; Dinsmore, et al. 2008). Since having been shown to be a valid measure in educational psychology, the self-regulation concept and measures of it in individuals have become popular, as well, in research on second language learning. Use of language learning strategies is increasingly understood in terms of self-regulation (e.g., Tseng, Dörnyei, \& Schmitt, 2006). 
Self-regulated learning is achieved through a set of social, cognitive and meta-cognitive strategies. These, according to Zimmerman (1989), fall into two categories: "self-efficacy perceptions" and "strategy use".'Self-regulated learners, according to Zimmerman, are people who "plan, organize, self-instruct, self-monitor, and self-evaluate at various stages of the learning process" (p. 308). Wenden (1998) distinguished self-regulated learning from another, closely related concept; namely, self-directed learning. He explained that self-regulated learning is a construct relevant to psychology research, whereas self-directed learning is a construct pertinent to adult education and often related with learner autonomy.

\subsection{Self-directed Learning}

Self-directed learning driven by internal and external motivations for language learning and includes planning and managing the learning task, as well as concepts and attitudes that influence learning. Significant effort has been devoted to distinguishing self-directedness from similar and closely related frameworks and concepts learning strategy research (e.g., Wenden, 1998; Saks \& Leijen, 2014).' In their detailed exposition of the distinction between the two concepts, Saks and Leijen (2014) postulate that self-regulated learning is a more general framework and it emphasizes the interaction between a learner's behavioral and affective regulation and the environment. Self-directed learning is concerned with self-management behavior and cognition, and control over them. It is often associated with adult education, although it is not necessarily limited to that domain. Both frameworks involve four steps of learning: (1) task defining, (2) goal setting, (3) enacting/controlling, and (4) reflection and evaluation (Wenden, 1998; Saks \& Leijen, 2014). One of the frameworks in self-directed learning research that is most useful to the present enquiry is that of Garrison (1997). It includes constructs that have been found to yield significant findings in describing the learning process, and in identifying problems in language learning. Garrison's view of self-directedness includes three parameters: self-management, self-monitoring and motivation. Self-management, according to Garrison (1997), pertains to the control learners have over their planning and learning behavior. In other words, it concerns managing the practices that a learner perceives to be useful in learning.' The second parameter concerns self-monitoring. This is manifested in the control learners have over their behavioral and cognitive processes. Self-monitoring also includes learners' readiness to take responsibility for the learning task. Motivation is the third construct of Garrison's (1997) framework and it includes perceptions of one's ability and attitude towards learning. Motivation, according to Garrison, can be the inner drive to initiate a task or decide on a learning activity, "entering motivation," or motivation to sustain the learning activity, "Task motivation".

In general, motivation is essential to every activity within self-directed learning. Garrison's model of self-directedness is relevant for the purposes of this study in that it puts emphasis on the individual learner. The questionnaire items used in this study were constructed based on the author's understanding of Garrison's (1997) model, guided by definitions and examples of three of Garrison's dimensions of self-directedness. However, some constructs were adapted from Guglielminos (1978), who identified eight factors underlying readiness for self-directed learning. These include, "openness to learning opportunities, self-concept as an effective learner, initiative and independence in learning, informed acceptance of one's responsibility for one's learning, love of learning, creativity, future orientation and ability to use basic study, and problem solving skills" (Benson, 2013, p. 95). Guglielmino's (1978) scale for readiness for self-directed learning has become popular amongst researchers in health and business fields as well as education. It was commercialized and researchers were allowed to add other variables to suit their objectives in measuring self-directedness. However, Guglielmino's (1978) scale has been criticized for its tendency to measure attitudes towards learning in general, rather than the metacognitive characteristic of self-directed learning (Benson, 2013).

One of the less popular, but relevant, models of self-directedness is that of Candy (1991, cited in Benson, 2013), who portrays "self-directed learning as a general term that encompasses autonomy, self-management, learner-control and the individual, non-institutional pursuit of learning opportunities in the natural societal setting "autodidaxy" (p. 23).

Other dimensions of self-directedness include the learner's realization of the amount of work needed, commitment to practice and spending time, seeking exposure to the language, and motivation. Self-perceptions related to these dimensions were reported by language learners in Benson and Lor's (1999) study of language learners' beliefs. However, Benson and Lor (1999) drew no distinctions among varying degrees of success achieved by language learners.

Measuring self-directed learning often leads to the suggestion that it be promoted amongst learners. Garrison (1997) pointed out the importance of self-directed learning in achieving quality outcomes from education. He stated, "self-direction is seen as a necessary process for achieving worthwhile and meaningful educational 
outcomes. It is associated with initiating learning goals, maintaining intention, and striving for quality outcomes. [they] enhance meta-cognitive awareness and create the conditions where students learn how to learn" (p. 31). Self-directed learning is the framework for this investigation. It has received enough attention in second language learning research that one may confidently set its parameters and trust its validity. However, it has almost never been operationalized when investigating language learning difficulties in the Saudi context, where educational and socio-cognitive factors, such as lack of opportunities for purposeful communicating in the target language, call for more agency and responsibility on the part of the learner.

Self-directedness has been investigated by second language learning researchers only to a very limited extent and often only implicitly. That is, researchers often report components of self-directed learning measures without explicitly adopting the framework of self-directedness. The objectives of this study are to develop an instrument to measure learners' self-directedness, to compare levels of self-directedness in successful versus low-achieving learners, to consolidate implications for teaching and learning English as a foreign language in the Saudi higher education context, and to consolidate, as well, implications for further research.

This study sets out to answer two research questions:

(1) Are there significant differences between successful and less-successful learners (defined in this study as Repeaters and Non-repeaters) in terms of self-directedness measures, including self-management, self-monitoring, motivation, and study time?

(2) Are there significant differences between successful and less-successful learners in GAT scores?

\section{Method}

\subsection{Participants}

37 young adult students at the English Language Institute (ELI) affiliated with a Saudi university participated in the study. All of them are female first year college students attending English language courses in the university's Preparatory Year Program. 17 of the participants were at the program's level four (CERF, assumed level, B1+); 20 at level three (CERF, assumed level, B1). All the participants had begun English study at the ELI in September, 2015 at entry level one (CERF, assumed level, A1). The level four students in the study are those who had progressed successfully, such that, at the time of data collection, they are in their last required academic level.'The level three students, however, are those who were unsuccessful in passing one of the levels in the program sequence and so are required to repeat a level at the ELI. In the sample analyzed for this study, all these latter happened to have failed level three and were taking it again at the time of data collection. Thus, the study comprises two participant groups: students more successful versus less successful in EFL, referred to as Non-repeaters and Repeaters, respectively. Each group is a convenience sample.

\subsection{Material}

The data collection instrument was a questionnaire designed by the author for the purpose of this study. The general framework guiding design of the questionnaire was Garrison's (1997) model of self-directed learning. The individual questionnaire items were developed with reference to the constructs of self-directed learning and self-regulated learning described mostly in Garrison (1997), but include a number of items adapted from similar enquiries in previous studies (e.g., Cotterall, 1995; Guglielmino, 1977). The number of items in the questionnaire was purposefully kept small. This decision was motivated by past experiences of researchers in the ELI context who have repeatedly observed that students have little inclination to spend time responding to questionnaires.

The questionnaire starts with factual information probes, such as level of study and whether the students have repeated any of the course levels. Then the main battery of self-directedness items was divided according to three constructs, reflecting Garrison's dimensions. These are self-management, self-monitoring and motivation. Building the items for each construct was guided by Garrison's definitions, as well as by Cotterall's (1995) and Guglielmino's (1978) exemplifications. Self-management and task control items described instances of behavioral manifestations of learning aims and of proactive learning (i.e., what learners do). Garrisons calls them "external management dynamics" (p. 23). An example of managing the learning context would be to search for instances of new vocabulary usage using the Internet. Self-monitoring is "the responsibility to construct meaning ... through critical thinking and collaborative conformation" (Garrison, 1997, p. 24). Self-monitoring is involved in task management but it differs from self-management in that it entails responsibility, while self-management entails control. Manifestations of self-monitoring would include reflecting on one's learning (critical thinking) and seeking the help of a teacher or peers (collaborative conformation). The third construct in Garrison's model is motivation. It "reflects perceived value and anticipated success of learning goals at the time learning is initiated and mediated between context (control) and cognition (responsibility) during the learning 
process" (Garrison, 1997, p. 26). Items measuring openness for opportunity and self-concept of self-efficacy were added under self-management and motivation, respectively.

Table 1 shows how some items in the questionnaire were constructed according to Garrison's constructs of his three dimensional model.

Table 1. Dimensions of the self-directedness measures and examples

\begin{tabular}{|c|c|}
\hline n's dimensions & xamples of items in the \\
\hline $\begin{array}{l}\text { Garrison's dimension } \\
\text { Self-managements }\end{array}$ & $\begin{array}{l}\text { - I keep a list of new vocabulary. } \\
\text { - } \quad \text { When I look up a word I read the examples of sentences provided in the }\end{array}$ \\
\hline & $\begin{array}{l}\text { explanation. } \\
\text { - I Google the new word to see how it is used in another context. }\end{array}$ \\
\hline Exposure to content/ & - I use Google to search in English for information, such as recipes. \\
\hline $\begin{array}{l}\text { Openness to opportunity } \\
\text { (self-management) }\end{array}$ & $\begin{array}{l}\text { - I watch English movies. } \\
\text { - I try and speak in English when I meet non-Arabs. }\end{array}$ \\
\hline $\begin{array}{l}\text { Garrison's dimension } \\
\text { Self-Monitoring } \\
\text { (responsibility) }\end{array}$ & $\begin{array}{l}\text { - } \quad \text { I often write diaries about my learning. } \\
\text { - } \quad \text { I discuss my progress with my teacher. } \\
\text { - } \quad \text { I turn to my classmate and check if we have the same answer (without }\end{array}$ \\
\hline $\begin{array}{l}\text { Garrison's dimension of } \\
\text { Motivation (entering and task) }\end{array}$ & $\begin{array}{l}\text { - I am enjoying learning English } \\
\text { - It is important to take these English courses in the preparatory year }\end{array}$ \\
\hline Self-efficacy & $\begin{array}{l}\text { - The material is good and is helping us to learn English } \\
\text { - The number of hours is suitable for the purpose of this course. } \\
\text { - } \quad \text { I am an effective learner. }\end{array}$ \\
\hline
\end{tabular}

The questionnaire was delivered in Arabic because the participants' English proficiency was too low-level to understand the questions and respond accurately.

\section{Results}

Thirty-seven students in two course sections, one level three and one level four, responded to the questionnaires. Four respondents were excluded because of incomplete response and one was randomly excluded to equalize the number of cases in each of the two groups: the Repeaters and the Non-repeaters. The resulting total number of participant samples was 32 .

The questionnaire responses were first tested for reliability using Cronbach's Alpha. The self-directedness items of all three constructs - self-management, self-monitoring and motivation and attitude - were found to have high internal consistency, having a reliability coefficient of .896 (Table 2). Similarly, items within each construct were also found to be highly consistent, with motivation items having the least consistency score $(0.799)$.

Table 1. Reliability of the measures

\begin{tabular}{llll}
\hline Scale Label & Cases & N of Items & Cronbach's Alpha \\
\hline Self-management & 32 & 14 & 0.799 \\
Self-monitoring & 32 & 11 & 0.821 \\
Motivation & 32 & 7 & 0.702 \\
Self-directedness & 32 & 32 & 0.896 \\
\hline
\end{tabular}

A scale of self-directedness for individual participants was computed by summing up the level of agreement for all the items across the self-directedness constructs. Then the items within each of the three constructs were 
computed to calculate a total score of the items. This was needed to generate a scale for the three constructs: self-management, self-monitoring and motivation and attitude. Developing the scales was necessary in order to be able compare tendencies for each of the measurement dimensions, as well as compare general readiness for self-directedness. Following this, an independent sample t-test was run using the independent variable (Repeater versus Non-repeater) as the grouping variable. Table 3 displays mean differences between the two groups and standard deviations for GAT scores, number of hours spent studying, and scores for self-management, self-monitoring, motivation, and attitude.

Table 2. Group statistics of the dependent variables

\begin{tabular}{llllll}
\hline & Repeat & $\mathrm{N}$ & Mean & Std. Deviation & Std. Error Mean \\
\hline \multirow{2}{*}{ General Aptitude Test } & Non-repeaters & 16 & 71.2500 & 8.15271 & 2.03818 \\
& Repeaters & 16 & 75.5625 & 7.57160 & 1.89290 \\
Study time & Non-repeaters & 16 & 7.1250 & 2.10950 & .52738 \\
& Repeater & 16 & 4.4688 & 2.23210 & .55803 \\
Self-Management & Non-repeaters & 16 & 26.2500 & 4.26615 & 1.06654 \\
& Repeater & 16 & 22.9375 & 4.59665 & 1.14916 \\
Self-Monitoring & Non-repeater & 16 & 25.7500 & 3.49285 & .87321 \\
\multirow{3}{*}{ Motivation } & Repeater & 16 & 23.6250 & 3.70360 & .92590 \\
& Non-repeater & 16 & 20.6875 & 3.21908 & .80477 \\
Self-directedness Total & Repeater & 16 & 18.5000 & 3.79473 & .94868 \\
& Nonrepeater & 16 & 72.6875 & 8.66963 & 2.16741 \\
& Repeater & 16 & 65.0625 & 10.69248 & 2.67312 \\
\hline
\end{tabular}

The table shows differences in the means of Repeaters and Non-repeaters groups in GAT, the study time, total score of self-directedness, as well as in all of the three constructs of self-directedness when calculated separately.

The independent-samples t-test shows that the two groups (Non-repeaters and Repeaters) exhibit significant differences in three of the measures: the total score for self-directedness scale $(t=2.216, p=0.034)$, the self-management scale $(t=2.113, p=0.043)$ and study time $(t=3.46, p=0.002)$. Differences between the means in the other constructs (self-monitoring and motivation scales) were not statistically significant.

\section{Discussion}

The purpose of this study was to measure and compare the self-directedness of learners grouped in two different academic profiles: those who have progressed normally through the levels of an English course (Non-repeaters) and those who have failed one or more of the course levels and were repeating it at the time of data collection (Repeaters). The goal was to find out whether there are significant differences between these two groups in terms of self-directedness measures, as well as in general aptitude.

Evidence from the independent sample t-test for similarity of group means leads to rejecting the null hypotheses that there are no significant differences between Non-repeaters and Repeaters in self-directedness $(t=2.216, p=$ $0.034)$ and in the component measure of self-management $(t=2.113, p=0.002)$. In other words, Non-repeaters and Repeaters are different in their general tendency for self-directed learning and, in particular, they are different in relation to the measures of self-management. This shows the relevance of learning behavior to language learning success.

There also is a significant difference in study time between Non-repeaters and Repeaters $(t=3.46, p=0.002)$. This suggests that study time is a predicator of success in learning. Study time, as stated above, is a measure considered by many researchers to tap the self-management abilities of learners (Benson \& Lor, 1999). Study time was included in a separate measure because measuring it in terms of a Likert scale (with a limited number of choices) would not yield accurate data. However, it is an example of task control and thus it gives some indication of self-management. In general, the construct of self-management appeared as a strong predictor of language learning success. This supports Gan's, et al. (2004) conclusions based on their qualitative research. Successful students ascribed their success to factors that stem from self-management skills, including controlled 
strategies and efforts, goal setting, identifying learning problems and making use of learning and practicing opportunities. This also supports Elyas (2014), where successful students, in narrating their stories, attributed their success to "self-correct and self-improve" (p. 33). On the other hand, students who reported on their "failure stories" exhibited lack of confidence, and blamed the others for their failure. There were no significant differences between the Non-repeaters and Repeaters in terms of motivation measures, in isolation. Accordingly, the null hypothesis that there is no significant difference between successful and less-successful learners in terms of motivation and attitude measures cannot be rejected. The reason for this could simply be that learners in the two groups do not differ in their motivating and attitude, or that motivation, or lack thereof, has no effect on achievement in language learning. The latter possibility is in accord with Noels', et al. (2000) claim that enjoying learning does not lead to more involvement in the task of learning. Learners, according to Noels and colleagues, have to perceive learning a language as important to them and not merely enjoyable. A closer look at the items within the motivation construct supports the first explanation, that participants share positive or negative attitudes towards the learning situation at ELI and this is why differences between the groups were not significant. For example, $96.9 \%$ of respondents agreed or strongly agreed that it is essential to learn English. Further, respondents had almost equal levels of agreement with the statements, "It is essential to study English in the Preparatory year" and "The English book is good and it facilitates learning." Finally, respondents all shared a very negative attitude toward the statement, concerning the number of weekly teaching hours, "the number of class hours per week is appropriate." $90.6 \%$ of all participants disagreed or strongly disagreed with this last statement.

Similarly, there is no significant difference between successful and less-successful learners in terms of self-monitoring measures. The null hypothesis cannot be rejected. Frequency measures of data offer the same explanation as with motivation, learners seem to share similar self-monitoring and responsibility attributes. For example, $93.7 \%$ of the students in both groups disagreed or strongly disagreed with the statement about asking for help from peers; and also 84.4 disagreed or strongly disagreed with the statement "I try to use the English words and expressions I learn." Similar disagreement levels were detected in responses to other self-monitoring items, such as reflecting on learning with peers, and seeking help from teachers. This shows an alarmingly low level of "collaborative conformation," to use Garrison's term. One of the seemingly most paradoxical finding in this study is the difference between scores on the GAT for the Non-repeaters and Repeaters. The Repeaters reported higher general aptitude scores than the Non-repeaters. The difference, however, isn't statistically significant $(p=0.132)$. The counter-intuitive finding that successful students have lower GAT scores than the less-successful ones could be attributed to inaccuracy on the part of the participants in reporting their scores. Other reasons could be the relatively small sample size or and the lack of large discrepancy between the levels of the two groups. Both groups were placed at level one at the start of the year. Findings of this study have also revealed a correlation between some of the constructs. Self-monitoring was found to correlate positively, though mildly, with self-management and motivation, and there was a weak correlation between self-management and motivation (all significant at the 0.01 level). However, no correlation was found between self-management and self monitoring. This doesn't lend support to Garrison's view of the relationship between the two constructs. He stated, "Although theoretically they go hand in hand, it is very difficult for learners to assume responsibility for their own learning [self-mentoring] without feeling they have some control over the educational transaction [self-management]." This could be due the limited amount of control the students at the ELI have over the learning process. It is very important at this stage to mention that the distinction between the two groups may not be the strongest we could have found among Preparatory year students, had we utilized a different approach to sampling for the study. The two groups had both started the academic year placed in level one (of the four levels in the Preparatory year program). More significant differences may have emerged from this study had we compared Repeaters to those students who had progressed normally beginning at level three, or those who were placed directly in level four. However, due to the timing of the study (during the last module of the academic year) the only students available were those who had begun the academic year in level one. The distinction between them was on the basis of progressing successfully through the course levels or failing one or more course levels. We had lost track of students who were initially placed in levels two, three, and four. An investigation that included learners of more stratified proficiency levels would be necessary to support stronger insights into the correlation between self-directedness behavior and cognition and learners' success. A future research effort will therefore be to duplicate this study at the beginning of a Preparatory year, in order to investigate more distinct groups of learners.

\section{Conclusion and Implications for Teaching and Further Research}

The present study adopts Garrison's three-dimension model that approaches the notion of self-directedness from 
the perspective of the individual. This model provided the constructs necessary to examine self-directed learning in the specific population samples observed for this study. Results provided enough evidence of significant differences between successful and less-successful learners, in terms of self-directedness, to allow us to claim that attributes of self-management and task control can predict success in language learning, especially since the instrument used in measuring self-directedness proved to have reliable internal consistency. However, it is important for further research to consider contextual factors such as institutional constraints and classroom dynamics. A lot needs to be known about the study population on which this study drew, in terms of how useful the English courses are in students' subsequent content courses and whether or not students' agency in language learning will support their progress in content courses where English is the language of instruction. Perhaps one of the interesting questions that could guide further investigation is whether or not these context-specific factors undermine self-directedness in language learning is Saudi university students. A future study will also need to address the language learning success measure that was defined, in this study, as the ability to progress through the academic levels one after another. Success and failure in summative exams may not be a valid measure for language learning, although it's a seemingly a plausible measure in an academic context. The author of this study hopes, in particular, to find out through future enquiry if promoting a learner's agency in and control over the learning process can result in higher achievement in language learning, measured in different ways. Promoting learners' autonomy and self-efficiency could include training learners on goal setting, self-efficiency strategies, taking responsibility and reflecting on the learning process and product. Effective learning is unlikely to be a spontaneous.' Oxford (1990) calims that "although learning is certainly part of the human condition, conscious skill in self-directed learning and in strategy use must be sharpened through training" (p. 201). Strategy training will probably increase learners' self-directedness and autonomy alongside motivation, and complaints about university EFL students (at least in the context of the present study) as being passive and de-motivated will be addressed. In particular, for students who will continue their college years in content areas where English is the main language of instruction and assessment, there is a need to plan self-directedness strategy training. In doing so we could benefit from well-established models of strategy training, such as the one developed by O'Malley and Chamot (1990).

\section{References}

Al-Hazmi, S. (2003). EFL teacher preparation programs in Saudi Arabia: Trends and challenges. Tesol Quarterly, 37(2), 341-344. http://dx.doi.org/10.2307/3588509

Al-Nasser, A. S. (2015). Problems of English Language Acquisition in Saudi Arabia: An Exploratory-cum-remedial Study. Theory and Practice in Language Studies, 5(8), 1612-1619. http://dx.doi.org/10.17507/tpls.0508.10

Al Shumaimeri, Y, A. N. (2003). A Study of Class Room Exposure to Oral Pedagogic Tasks in Relation to the Motivation and Performance of Saudi Secondary Learners of English in a Context of Potential Curriculum Reform. (Unpublished Ph.D. Thesis). University of Leeds, Leeds, UK.

Benson, P. (2013). Teaching and Researching: Autonomy in Language Learning. Routledge.

Benson, P., \& Lor, W. (1999). Conceptions of language and language learning. System, 27(4), 459-472. http://dx.doi.org/10.1016/S0346-251X(99)00045-7

Candy, P. C. (1991). Self-Direction for Lifelong Learning. A Comprehensive Guide to Theory and Practice. San Francisco, CA: Jossey-Bass.

Clément, R., Dörnyei, Z., \& Noels, K. A. (1994). Motivation, self - confidence, and group cohesion in the foreign language classroom. Language Learning, 44(3), 417-448. http://dx.doi.org/10.1111/j.1467-1770.1994.tb01113.x

Cotterall, S. (1995). Readiness for autonomy: Investigating learner beliefs. System, 23(2), 195-205. http://dx.doi.org/10.1016/0346-251X(95)00008-8

Cotterall, S. (1999). Key variables in language learning: What do learners believe about them? System, 27(4), 493-513. http://dx.doi.org/10.1016/S0346-251X(99)00047-0

Cotterall, S., \& Murray, G. (2009). Enhancing metacognitive knowledge: Structure, affordances and self. System, 37(1), 34-45. http://dx.doi.org/10.1016/j.system.2008.08.003

Creswell, J. W. (2013). Research Design: Qualitative, Quantitative, and Mixed Methods Approaches. Sage Publications

Dinsmore, D. L., Alexander, P. A., \& Loughlin, S. M. (2008). Focusing the conceptual lens on metacognition, 
self-regulation, and self-regulated learning. Educational Psychology Review, 20(4), 391-409. http://dx.doi.org/10.1007/s10648-008-9083-6

Dörnyei, Z., \& Ushioda, E. (2013). Teaching and researching: Motivation. Routledge.

Elyas, T. (2014). Exploring Saudi Arabia's EFL Student Identity: A Narrative Critical Approach.'International Journal of Applied Linguistics and English Literature, 3(5), 28-38.

Elyas, T., \& Al-Grigeri, W. (2014).'Obstacles to Teaching English in Saudi Arabia Public Schools: Teachers' and Supervisors"Perceptions. International Journal of English Language Teaching, 2(3), 74-89.

Elyas, T. (2012). Diverging identities: 'a contextualized' exploration of the interplay of competing discourses in two Saudi university classrooms. Journal and Proceedings of the Royal Society of New South Wales, 144(3\&4), 110 .

Elyas, T., \& Picard, M. (2012). Towards Globalized'Notion of'Teaching'English'in Saudi Arabia: A Case Study. Asia EFL, 41(2), 120-136.

Elyas, T. (2011). Teacher Education and Identity in Saudi Arabia and Real-life Conflicts: A Case Study. In C. Coombe, L. Stephenson, \& S. Abu Rmaileh (Eds.), Leadership and Management in English Language Teaching (pp. 137-148). Dubai: TESOL Arabia Publications.

Elyas, T., \& Picard, M. (2010). Saudi Arabian Educational History: Impacts on English Language Teaching. Education, Business and Society: Contemporary Middle Eastern Issues, 3(2), 24-40. http://dx.doi.org/10.1108/17537981011047961

Elyas, T. (2008). The Attitude of American English within the Saudi Education System.'Novitas-ROYAL Research on Youth and Language, 2(1).

Fareh, S. (2010). Challenges of teaching English in the Arab world: Why can't EFL programs deliver as expected? Procedia Social \& Behavioral Science, 2, 3600-3604. http://dx.doi.org/10.1016/j.sbspro.2010.03.559

Gan, Z., Humphreys, G., \& Hamp - Lyons, L. (2004). Understanding successful and unsuccessful EFL students in Chinese universities. The Modern Language Journal, 88(2), 229-244. http://dx.doi.org/10.1111/j.0026-7902.2004.00227.x

Garrison, D. R. (1997). Self-directed learning: Toward a comprehensive model. Adult Education Quarterly, 48(1), 18-33. http://dx.doi.org/10.1177/074171369704800103

Guglielmino, L. M. (1978). Development of the self-directed learning readiness scale. (Doctoral dissertation, University of Georgia, 1977). Dissertation Abstracts International, 38, 6467A.

Holec, H. (1981). Autonomy and Foreign Language Learning. Pergamon, Oxford, UK.

Khan, I. A. (2011). Learning difficulties in English: Diagnosis and pedagogy in Saudi Arabia. Educational Research, 2(7), 1248-1257.

Noels, K. A., Pelletier, L. G., Clément, R., \& Vallerand, R. J. (2000). Why are you learning a second language? Motivational orientations and self - determination theory. Language Learning, 50(1), 57-85. http://dx.doi.org/10.1111/0023-8333.00111

O’Malley, J. M., \& Chamot, A. U. (1990). Learning Strategies in Second Language Acquisition. Cambridge, England, Cambridge University Press. http://dx.doi.org/10.1017/cbo9781139524490

Oxford, R., \& Nyikos, M. (1989). Variables affecting choice of language learning strategies by university $\begin{array}{lllll}\text { students. The Modern } & \text { 291-300. }\end{array}$ http://dx.doi.org/10.1111/j.1540-4781.1989.tb06367.x

Oxford, R. L. (1990). Language Learning Strategies. What Every Teacher Should Know. Boston: Heinle, Cengage Learning.

Rubin, J. (1975). What the "good language learner" can teach us. TESOL quarterly, 9(1), 41-51. http://dx.doi.org/10.2307/3586011

Saks, K., \& Leijen, Ä. (2014). Distinguishing self-directed and self-regulated learning and measuring them in the e-learning context. Procedia-Social and Behavioral Sciences, 112, 190-198. http://dx.doi.org/10.1016/j.sbspro.2014.01.1155

Thanasoulas, D. (2000). What is learner autonomy and how can it be fostered. The Internet TESL Journal, 6(11), 
$37-48$.

Tseng, W. T., Dörnyei, Z., \& Schmitt, N. (2006). A new approach to assessing strategic learning: The case of self-regulation in vocabulary acquisition. Applied Linguistics, 27(1), $78-102$. http://dx.doi.org/10.1093/applin/ami046

Wenden, A. L. (1998). Metacognitive knowledge and language learning1. Applied linguistics, 19(4), $515-537$. http://dx.doi.org/10.1093/applin/19.4.515

Zimmerman, B. J. (1989). A social cognitive view of self-regulated academic learning. Journal of educational psychology 81(3), 329. http://dx.doi.org/10.1037/0022-0663.81.3.329

Zimmerman, B. J., \& Bandura, A. (1994). Impact of self-regulatory influences on writing course attainment. American Educational Research Journal, 31(4), 845-862.

\section{Copyrights}

Copyright for this article is retained by the author(s), with first publication rights granted to the journal.

This is an open-access article distributed under the terms and conditions of the Creative Commons Attribution license (http://creativecommons.org/licenses/by/3.0/). 